\title{
A New Chapter for the Journal
}

\author{
Gilbert Herdt • Brian de Vries
}

Published online: 6 March 2010

(C) Springer Science+Business Media, LLC 2010

This issue of Sexuality Research and Social Policy (SRSP) marks a milestone in the journal's history, as we have moved to a new publisher, Springer Science+Business Media. This partnership signals a new profile and growth of the journal, now in 2010, entering its seventh year. We are excited to join forces with Springer (www.springer.com), a leading global scientific publisher of books and journals. In the science, technology, and medicine sector, the group publishes about 2,000 journals and more than 6,500 new books a year, as well as the largest eBook Collection worldwide. Springer has operations in about 20 countries in Europe, USA, and Asia, and more than 5,000 employees. As the field of sexuality research and policy continues to advance and grow, our new association with Springer ensures an international platform and ever-increasing readership for the journal.

SRSP began as a publication of the National Sexuality Resource Center and was initially supported by the Ford Foundation and housed at San Francisco State University. However, it quickly moved to the University of California Press, which in 2005 began publishing the journal and shepherded its growth through five volumes and 20 issues including over 125 original empirical and theoretical articles. The many relevant, timely, and important topics published in the journal reflect major themes in the field, such as high-profile research and themed issues related to evaluation of abstinence-only programs, HIV/AIDS and criminalization, disability and sexual rights, sexuality and aging, to name a few of the host of significant areas. The authors and guest editors have been among the leaders in their fields, and their contributions in this journal have been cited in many other research venues, media, and congressional briefings.

We look forward to this next stage in the development of this journal and the field through an expansion of the reach and ground of Sexuality Research and Social Policy, building upon the increasing popularity and respect it has received and the publishing resources of Springer. For example, the journal will now offer both an online and print version, as well as publishing "on demand." Springer's Online First functionality promises fast publication, as accepted papers are published online as soon as they are finalized, often months ahead of scheduled issue publication dates.

Thank you for your continued interest in the journal and your contributions to its pages. We would like to invite you to consider new submissions to the journal in the coming months and years. Please visit the journal's homepage (springer.com/13178) for author instructions and other information. When visiting, please sign up for SpringerAlerts for this journal-it's easy and free, and you'll receive notice when each issue of the journal is published.

G. Herdt $\cdot$ B. de Vries $(\bowtie)$

San Francisco State University,

1600 Holloway Avenue,

San Francisco, CA 94132, USA

e-mail: bdevries@sfsu.edu 